\title{
Earthquake relocations, fault zone geometry and constraints on lateral velocity variations using the joint hypocenter determination method in the Taiwan area
}

\author{
Kwang-Hee $\mathrm{Kim}^{1,2 *}$, Jer-Ming Chiu ${ }^{1}$, Jose Pujol ${ }^{3}$, and Kou-Cheng Chen ${ }^{2}$ \\ ${ }^{1}$ Center for Earthquake Research and Informaion, The University of Memphis, Memphis, TN 38152, USA \\ ${ }^{2}$ Institute of Earth Sciences, Academia Sinica, Nankang, Taipei, Taiwan \\ ${ }^{3}$ Department of Earth Sciences, The University of Memphis, Memphis, TN 38152, USA
}

(Received December 14, 2004; Revised March 21, 2005; Accepted June 26, 2005)

\begin{abstract}
Four subsets of earthquakes recorded by an island-wide seismic network from 1991 to 2002 in the Taiwan area are relocated using the joint hypocenter determination (JHD) technique. Relatively large horizontal and vertical shifts are observed during the relocation, which indicates there may be systematic earthquake miss-locations in the Taiwan earthquake catalog due to the over-simplification of complicated earth structures to a simple 1-D velocity model. Generally, earthquakes are more clustered after the JHD relocation. Subsurface structures defined by the relocated seismicity become clearer, while they are not as clear in the initial hypocenters. Significant subsurface structures defined by the relocated seismicity are fault systems beneath the Central Mountain Range, beneath the northern Longitudinal Valley and Coastal Range, beneath the southern Longitudinal Valley and Coastal Range, and beneath the Chao-Chou fault in southern Taiwan. Another set of results from the JHD analysis, $P$ - and $S$-wave station corrections, provide valuable information on the lateral velocity variations. The JHD station corrections indicate that upper crustal materials in the Central Mountain Range are characterized by higher velocity than those in the Western Foothills and Coastal Plain. The patterns of the observed JHD station corrections are also thoroughly consistent with surface geology observations. Analysis of the four clusters of earthquakes resulted in a remarkable similarity in JHD station corrections, indicating that the overlapping subsurfaces where two or more clusters of rays had traveled through were relatively shallow. These subsurfaces are responsible for the observed patterns of positive and negative JHD station corrections.
\end{abstract}

Key words: Earthquake location, fault zone geometry, joint hypocenter determination, station corrections, velocity variation, Taiwan.

\section{Introduction}

Precise earthquake location has been one of the primary research objectives in seismology since seismic data were available because it provides initial insight into observed seismicity and faults or subsurface structures responsible for the observations. The quality of the locations is affected by limitations imposed by the quality of the data (available phases, signal-to-noise ratio, clock accuracy, the accuracy of arrival times, etc.), station distribution, prior information of the velocity structure in the area, techniques for location, and others. These limitations have been reduced by denser and wider seismic station coverage providing higher quality data and improved earth velocity models. Despite these improvements, there is still room for better earthquake location. In addition, the assessment of the result quality is not easy since precise source parameters and velocity structures of the selected study areas are usually not available. The same difficulties apply to the determination of earth-

\footnotetext{
*Now at Korea Ocean Research and Development Institute (KORDI), Ansan P.O. Box 29, Seoul 425-600, Korea.

Copyright (c) The Society of Geomagnetism and Earth, Planetary and Space Sciences (SGEPSS); The Seismological Society of Japan; The Volcanological Society of Japan; The Geodetic Society of Japan; The Japanese Society for Planetary Sciences; TERRAPUB.
}

quake hypocenters and origin times in the Taiwan area, although significant improvement has been achieved in terms of data quality and station coverage owing to an improved island-wide seismic network and a few local seismic networks. An evident problem in routine earthquake location is the over-simplification of the complex earth structure to a simple 1-D layered velocity model. Significant lateral velocity variations in Taiwan should exist because of the observed complicated surface geology. Many previous studies have provided velocity models on local and island-wide scales. However, the velocity structure in the Taiwan region is not well described by a 1-D layered velocity model. For example, basins along the Coastal Plain and the Western Foothills are filled with very low velocity sedimentary materials, while highly metamorphosed high-velocity materials are exposed on the Central Mountain Range. In addition, an extreme example of large lateral velocity variation has been recognized in southern Taiwan. The $P$-wave velocity of the shallow subsurface of the Pingtung basin in southwestern Taiwan is estimated to be as low as 1.8 to $2.2 \mathrm{~km} / \mathrm{sec}$ (Chen, 1998), while that of the southern Central Mountain Range can reach $5.8 \mathrm{~km} / \mathrm{sec}$. This mountain region is only several tens of kilometers away from the very low velocity basins, separated by the high-angle thrust 


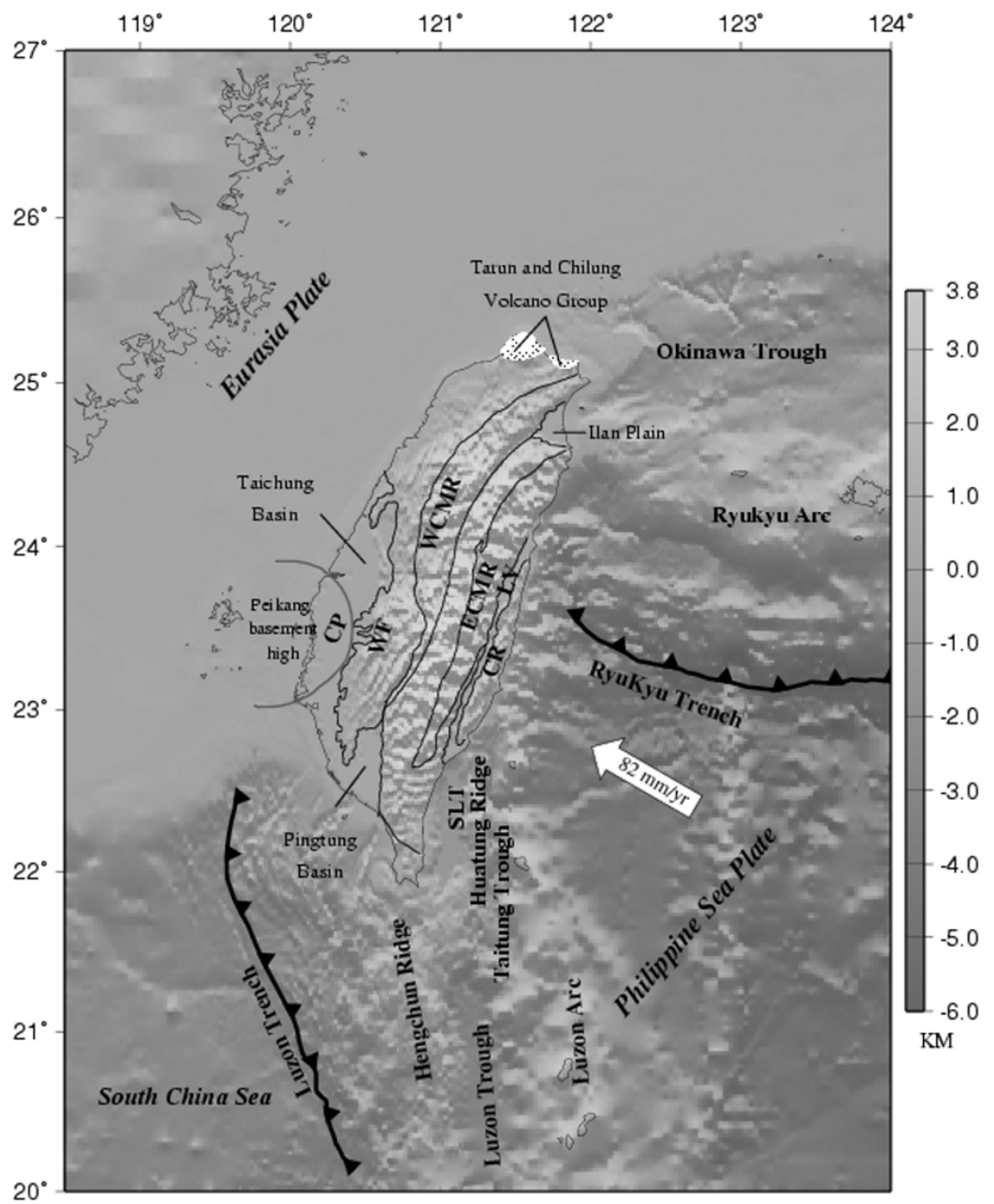

Fig. 1. Topography, bathymetry and tectonic setting of Taiwan and its surrounding area. The Philippine Sea plate is converging toward the Eurasian plate at a rate of $82 \mathrm{~mm} / \mathrm{yr}$ (Yu et al., 1997). General geological divisions in Taiwan are presented on top of the topography map (after Ho, 1988). They include CP: Coastal Plain, WF: Western Foothills, WCMR: Western Central Mountain Range, ECMR: Eastern Central Mountain Range, LV: Longitudinal Valley, and CR: Coastal Range. SLT: Southern Longitudinal Valley Trough.

\section{Chao-Chou fault.}

The earthquake location method known as the Joint Hypocenter Determination (JHD) technique has been applied to many data sets from different tectonic settings including, but not limited to, the New Madrid Seismic Zone in the central United States (Pujol et al., 1997; Mueller and Pujol, 2001), Loma Prieta mainshock-aftershock sequence (Pujol, 1995), Northridge mainshock-aftershock sequence (Pujol, 1996), the Campi Flegrei in Italy (Pujol and Aster, 1990), and southern Alaska (Ratchkovsky et al., 1997, 1998). Most previous studies of earthquake relocation using the JHD technique have produced significantly improved relative and even absolute earthquake locations. The JHD technique produces two important outcomes: improved earthquake parameters (hypocenters and origin times) and station corrections. It has been shown that the use of station corrections to represent the different con- ditions near the stations as well as along the ray paths is an efficient technique for obtaining better relative earthquake locations, and the patterns of station correction themselves can provide useful information regarding lateral velocity variations. However, potentially most effective method for minimizing model errors and achieving reliable earthquake locations is the use of 3-D velocity models that include lateral and vertical velocity variations as close as possible to those in the earth (Chen et al., 2005). Although earthquake location using 3-D velocity models is preferred, there are essential prerequisites that must be satisfied before it can be employed. These prerequisites are well-distributed seismic arrays, high quality data, and reliable forward and inverse techniques to obtain reliable 3-D $V_{P}$ and $V_{S}$ models. Furthermore, the velocity structure in the shallow subsurface of a study region may not be successfully recovered in a 3$D$ velocity model due to the inherent limitations in seismic 
ray geometry, as rays are almost parallel and incident to the surface almost vertically just beneath the stations. Under appropriate conditions, the JHD station corrections can be used to detect lateral velocity variations, including those at shallow depths, in a study area (Pujol, 1992).

In this study, four selected earthquake clusters are relocated to obtain better images of the seismicity and of the subsurface structures responsible for the observed seismicity. Our results show that the relocated earthquake hypocenters using the JHD technique are more clustered, and thus subsurface seismogenic structures are more easily observed. The JHD station corrections determined along with the earthquake parameters are discussed in terms of lateral velocity variations in the region. The performance of the method has been evaluated by a series of synthetic tests using realistic 3-D $P$-wave and $S$-wave velocity models.

\section{Seismotectonic Background}

One of the most active tectonic processes on earth is observed in and around the island of Taiwan where two plates-the Eurasian plate and the Philippine Sea plateare converging (Fig. 1). Taiwan's orogeny is relatively young on a geologic time scale. Evidence from sedimentation rate studies and paleomagnetism indicates that the Taiwan mountain building process started about 4 million years ago (Suppe, 1984). A high rate crustal deformation has been observed recently by a series of leveling and GPS observations (Yu and Liu, 1989; Angelier et al., 1997; Yu et al., 1997). Due to rapid deformation, Taiwan is one of the highest seismicity regions in the world. The most prominent seismic features in Taiwan and its surroundings are closely related to two active subduction systems, one in northeastern and the other in southern Taiwan, and a collision system separating these two subduction systems. The Philippine Sea plate is subducting beneath the Eurasian plate along the Ryukyu trench in the northeast of Taiwan and the South China Sea slab of the Eurasian plate is subducting beneath the Philippine Sea plate along the Luzon trench in the south of Taiwan. Geometries of the two subduction systems have been revealed by earthquake hypocenters from the top of the subducting slabs since modern instrument earthquake data were made available in the early 1970's (Tsai, 1986). Another prominent seismic pattern along the Longitudinal Valley, a surface representation of the two-plate collision, is also recognizable between the two subduction systems.

Taiwan can be subdivided into two major tectonic provinces separated by the Longitudinal Valley (LV). The eastern province consists of the Coastal Range (CR) and a few small islands. The CR is a remnant of a Neogene island arc, which is the leading edge of the Philippine Sea plate. Western Taiwan is generally believed to be associated with the Eurasian continental shelf (Ho, 1988) where crustal seismicity is widely distributed among various tectonic units. The western province can be subdivided into a few distinct NNE-SSW trending structural belts based on petrology. These tectonic units from west to east consist of the Coastal Plain (CP), the western Foothills (WF), the western Central Mountain Range (WCMR), and the eastern Central Mountain Range (ECMR). These units are often bounded by faults or differences in lithology, metamorphic grades and ages.

\section{Method}

The JHD technique has been used to improve relative earthquake locations and to quantify the lateral structural variations of shallow velocity structure. The method to determine earthquake parameters and station corrections was proposed by Douglas (1967) and improved by Pavlis and Booker (1983) and Pujol (1988). In general a onedimensional layered velocity model is used in routine earthquake location, although the real earth is much more complicated and cannot be represented properly by a simple 1-D layered velocity model. Consequently, errors due to the over-simplified earth structure are unavoidable. The essence of the JHD technique lies on its treatment of possible errors due to the over-simplified earth model. Errors are assumed to originate from the deviations of the velocity model from the real earth structure: (1) near the hypocenter, (2) near the station, and (3) along the ray path. Errors caused by the deviations of the velocity model near the source area can be ignored by selecting a cluster of earthquakes and locating them simultaneously. The other two error sources can be represented together in terms of "station correction" after disregarding irregularities near the earthquake hypocenters (Pujol, 1988). The JHD equations used to determine the hypocenters of $\mathrm{M}$ recorded by part of or all of a network of $N$ stations are written as:

$$
\begin{array}{r}
r_{i j}=d T_{j}+\frac{\partial t}{\partial x} d x_{j}+\frac{\partial t}{\partial y} d y_{j}+\frac{\partial t}{\partial z} d z_{j}+d s_{i} \\
i=1, N ; j=1, M,
\end{array}
$$

where

$$
r_{i j}=t_{i j}^{0}-t_{i j}=t_{i j}^{0}-\left(T_{j}+\tau_{i j}+s_{j}\right) .
$$

$t_{i j}^{0}$ is the observed arrival time, $t_{i j}$ is the computed arrival time based upon a 1-D velocity model. $t_{i j}$ is written again as the sum of the initially estimated origin time of the $j$ th earthquake, $T_{j}$, the computed travel time from the $j$-th earthquake with estimated location $\left(x_{j}, y_{j}, z_{j}\right)$ to the $i$-th station, $\tau_{i j}$, and the station correction for $i$-th station, $s_{i}$. $d T_{j}$ is the perturbation of the origin time for $j$-th earthquake. Note that the only difference of equation from that of the usual single event location procedure is the station correction term. In matrix form, Equation (1) is written as:

$$
\vec{r}_{j}=A_{j} d \vec{X}_{j}+S_{j} d \vec{s} ; j=1, M
$$

where $\vec{r}_{j}$ contains the residuals $r_{i j}, A_{j}$ is an $N \times 4$ matrix of partial derivatives computed at the source, $d \vec{X}_{j}$ is the vector of origin time and hypocenter adjustments, $S_{j}$ is an $N \times N$ diagonal matrix with ones for the station that recorded the earthquake and zeros otherwise, and $d \vec{s}$ is the vector of station correction adjustments to the $s_{i}$ 's. Multiplication of Eq. (3) by a matrix $W_{j}$ of quality weights gives:

$$
W_{j} \vec{r}_{j}=W_{j} A_{j} d \vec{X}_{j}+W_{j} d \vec{s} ; j=1, M .
$$

where $W_{j} S_{j}$ has been replaced by $W_{j}$. Equation (4) shows the coupling between earthquake locations and station corrections. The equation is solved using the singular value 


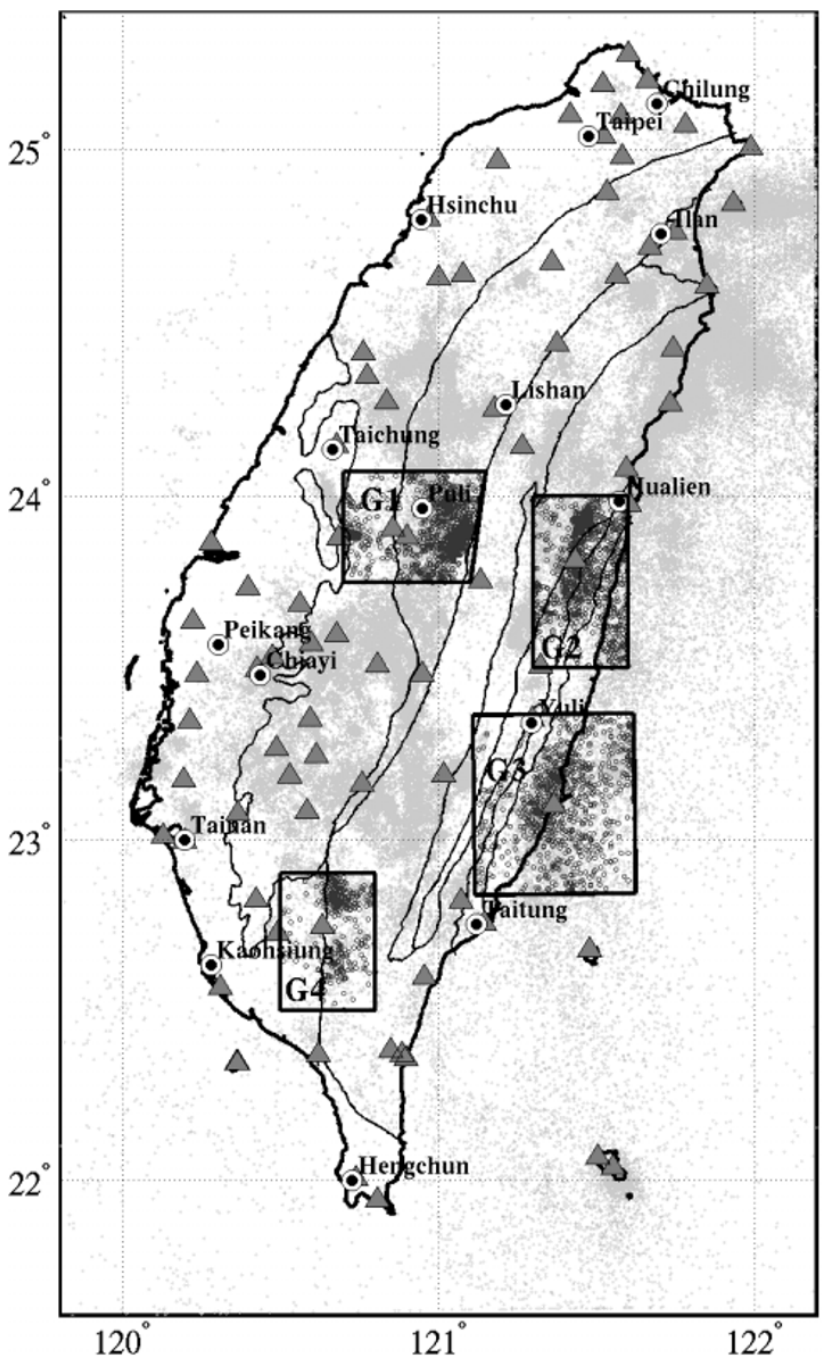

Fig. 2. Locations of four selected earthquake clusters (G1 to G4) for JHD analyses. Gray dots in the background are earthquake locations determined by the CWB between 1991 and 2002. Darker open circles are the selected earthquakes for this study. The CWB stations are shown by the closed triangles.

decomposition and least squares (Pavlis and Booker, 1983; Pujol, 1988). Earthquake locations using the JHD technique are generally believed to be more accurate in a relative sense, and less affected by the choice of velocity structure models than routine single event locations. In addition, in some cases improved absolute locations can be obtained (e.g., Pujol, 1995; Pujol et al., 1997).

Determination of earthquake hypocenters using the JHD technique is an iterative process while each iteration has two steps. Station corrections are determined in the first step of each iteration with current earthquake hypocenters and origin times. In the second step, earthquake hypocenters and origin times are determined in a least square sense using station corrections determined in the first step. In the next iteration, earthquake parameters and station corrections determined in the previous iteration are used as initial parameters. Station corrections may be interpreted in terms of lateral variations of the subsurface velocity structure which is not included in the 1-D layered earth model. Positive and negative JHD station corrections correspond to relatively
Table 1. 1-D velocity model used by the CWB for routine location (modified from Chen, 1995)

\begin{tabular}{ccc}
\hline Depth & $V_{P}$ & $V_{P} / V_{S}$ \\
\hline 0.0 & 3.48 & 1.73 \\
2.0 & 4.48 & 1.73 \\
4.0 & 5.25 & 1.73 \\
9.0 & 5.83 & 1.73 \\
13.0 & 6.21 & 1.73 \\
17.0 & 6.41 & 1.73 \\
25.0 & 6.83 & 1.73 \\
30.0 & 7.29 & 1.73 \\
35.0 & 7.77 & 1.73 \\
50.0 & 8.05 & 1.73 \\
70.0 & 8.16 & 1.73 \\
90.0 & 8.34 & 1.73 \\
\hline
\end{tabular}

lower and higher velocity anomaly along the ray path, respectively.

\section{Data}

Earthquakes in the island of Taiwan and its vicinity are monitored by the Taiwan Seismic Network (TSN) operated by the Central Weather Bureau (CWB). The TSN consists of 75 stations distributed on land and in some offshore islands (Wang and Shin, 1998). All the arrival time and earthquake location data from 1991 to 2002 from the TSN have been collected for this study. Earthquakes from four small regions have been selected, Group 1-Group 4 (Fig. 2). The events in Group 1 are located partially in the area of the $1999 M_{W}=7.6$ Chi-Chi earthquake (Shin et al., 2000) and its aftershocks in the center of the island of Taiwan. The seismically more active western Central Mountain Range is separated by events in this group from the aseismic eastern Central Mountain Range. The events in Group 2 are located in the Hualien area, in the northern Longitudinal Valley, where the most advanced collision is taking place. Earthquakes in Group 3 are selected from the southern Longitudinal Valley and Coastal Range. Events in Group 4 are located near the Chao-Chou fault in southern Taiwan, where significant topographic relief is observed across the fault.

A few selection criteria have been introduced to ensure the quality of earthquake data. Earthquakes with $P$-wave arrivals recorded at more than 12 stations and $S$-wave arrivals at more than 6 stations are selected for this study. Phase arrivals with low observation quality ( $>2$ or arrival time reading uncertainty larger than 0.3 second) have been excluded. Arrival time data with epicentral distance larger than $140 \mathrm{~km}$ are also excluded to better approximate a flat earth model. Snoke and Lahr (2001) have shown that the differential travel time between a spherical earth model and a flat earth model is less than 0.1 second for distances less than $187 \mathrm{~km}$ for a surface focus and $144 \mathrm{~km}$ for an event with a focal depth of $20 \mathrm{~km}$. Considering that most selected earthquakes occur at focal depths shallower than $30 \mathrm{~km}$, a cutoff epicentral distance of $140 \mathrm{~km}$ was selected.

Two additional criteria have been established to avoid numerical errors and poorly constrained earthquake relo- 



Fig. 3. Station corrections for events in Group 1. (a) JHD $P$-wave station corrections, (b) JHD $S$-wave station corrections, (c) JHD $P$-wave station corrections for the synthetic test, and (d) JHD $S$-wave station corrections for the synthetic test. The CWB seismic stations are marked by triangles. Stations selected for the JHD analysis for this group are shown as closed triangles. The number to the right of each closed triangle shows its corresponding JHD station correction.

Table 2. Average shift of origin time (second) and hypocentral location (km) of four groups of earthquakes after JHD relocation. DT: origin time shift; DEW, DNS: epicentral shift in E-W and N-S directions; DH: horizontal shift, DZ: depth shift (downward positive). Vertical bars indicate absolute value taken before averaging.

\begin{tabular}{lrrrrrrrrr}
\hline & $\overline{D T}$ & $\overline{|D T|}$ & $\overline{D E W}$ & $\overline{|D E W|}$ & $\overline{D N S}$ & $\overline{|D N S|}$ & $\overline{|D H|}$ & $\overline{D Z}$ & $\overline{|D Z|}$ \\
\hline Group1 & -0.10 & 0.20 & -3.09 & 3.09 & 0.59 & 0.83 & 3.26 & 0.19 & 1.47 \\
Group2 & 0.20 & 0.30 & 2.00 & 3.24 & -1.23 & 1.82 & 3.89 & 3.48 & 3.67 \\
Group3 & -0.26 & 0.37 & 0.26 & 2.63 & -1.31 & 2.28 & 3.94 & -1.17 & 2.38 \\
Group4 & 2.24 & 0.26 & -3.18 & 3.20 & 2.00 & 2.05 & 4.40 & -0.22 & 1.76 \\
\hline
\end{tabular}

cation. They are (1) the condition number for the matrix of partial derivatives has to be less than 150, and (2) the RMS residual shall not exceed 0.3 second for event Groups 1,2 and 4 or 0.4 second for event Group 3 in the last iteration. A relatively generous cutoff RMS has been applied for earthquakes in Group 3 because many events in the group are located slightly outside of the seismic network. Events whose focal depths become zero or negative (air quakes) in an iteration are also rejected.

We have not performed any aggressive search for a bet- ter 1-D island-wide velocity model for this study because the JHD technique is relatively insensitive to the choice of velocity model and station correction terms will approximately compensate for the deviations of the implemented velocity model from the real earth structure. Furthermore, previous studies of crust and upper mantle structural models have revealed large lateral structural variations across the island (Shih et al., 1998; Yeh et al., 1998) and different velocity models are often determined for local studies at different locations. However, to keep consistency throughout 




(a)



(c)



(b)

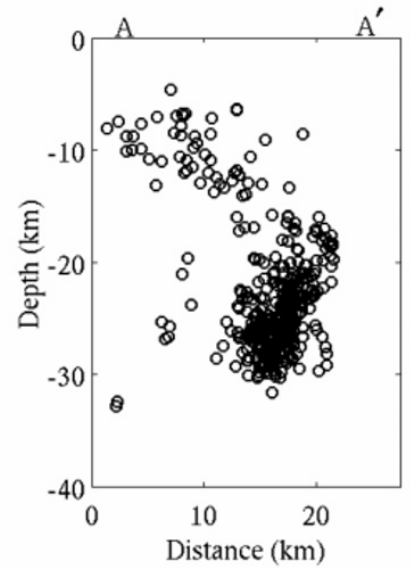

(d)

Fig. 4. Earthquake relocation using the JHD technique for the events in Group 1. (a) Initial earthquake locations determined and reported by the CWB, (b) earthquake epicenters after JHD relocation, (c) cross sectional view of the initial hypocenters determined by the CWB along A-A', and (d) cross-sectional view of the relocated hypocenters along A-A'.

the relocation of the 4 selected groups we used the velocity model used by the CWB for routine earthquake location (Table 1).

\section{Results}

After applying the data selection criteria described in the previous section, 1,085 events were selected for the JHD analysis in the first group. Some events were rejected during the analysis due to large arrival time residuals and/or a large condition number in the earthquake location. The number of earthquakes was reduced to 876 after 6 iterations. Most events have been systematically moved toward the west of their original locations with an average shift of 3.26 $\mathrm{km}$. Focal depths and origin times are slightly changed from their initial values, but by smaller amounts compared to shifts observed during the relocation of the other three groups. Hypocenter and origin time changes for the four selected groups after the JHD relocation are summarized in Table 2. For Group 1, The JHD station corrections vary over a large range: -0.91 to 0.81 second and -1.96 to 1.62 second for the $P$ - and $S$-waves, respectively (Fig. 3). The distribution of the station corrections shows negative values for the stations located in the Central Mountain Range and positive values for those located in the western Foothills and Coastal Plain for both $P$ - and $S$-waves. The west-dipping seismicity extending from 15 to $30 \mathrm{~km}$ depth is apparent before and after the relocation (Fig. 4), but the epicenters are considerably more clustered after relocation.

In the first iteration, Group 2 included 1,001 events that were reduced to 671 after the final iteration. The epicenters of the selected events were shifted an average of $3.89 \mathrm{~km}$ toward the southeast of the initial hypocenters. A significant downward depth shift $(3.48 \mathrm{~km})$ and small origin time advances on average ( 0.2 second) were observed after the JHD relocation. The patterns of $P$ - and $S$-wave station corrections are very similar to those observed in the first group, i.e. positive corrections in the Central Mountain Range and negative corrections for western Taiwan (Fig. 5). The station corrections for the Longitudinal Valley and the Coastal Range of eastern Taiwan are higher than the corrections for the Central Mountain Range but lower than those for the Western Foothills and Coastal Plain. The station corrections vary from -1.07 to 1.30 second and -2.35 to 1.61 second for the $P$ - and $S$-waves, respectively. Clustering of earthquake hypocenters after applying the JHD technique is clear. Major subsurface seismogenic structures can be readily identified after the JHD relocation (Fig. 6).

Group 3 consists of 811 earthquakes with 647 earthquakes remaining after five iterations. These earthquakes were moved, on average, toward the southeast of their initial hypocenters. In addition, many events are located shallower than their initial depths. Station corrections for both the $P$ and $S$-waves consistently show negative values for stations located in the Central Mountain Range (Fig. 7). Station cor- 



Fig. 5. Same as Fig. 3 but for Group 2.

rections for the $P$ - and $S$-waves vary from -1.41 to 1.07 second and from -2.73 to 1.80 second, respectively. The relocated hypocenters reveal a clear east or southeast dipping seismogenic structure (Fig. 8). Note that the dipping direction of the fault delineated by the relocated hypocenters in this group is opposite to that observed in Group 2.

The number of earthquakes was reduced from 346 to 242 after 6 iterations in Group 4. Large origin time shifts and large hypocenter shifts were observed. Station corrections vary from -0.84 to 0.55 second and from -1.15 to $1.71 \mathrm{sec}-$ ond for the $P$ - and $S$-waves, respectively. Again, negative station corrections were observed for the stations located in the Central Mountain Range (Fig. 9). Relocated hypocenters show a vertical seismicity trend beneath the Chao-Chou Fault (Fig. 10).

\section{Discussion}

\subsection{Synthetic tests}

Pujol (1995, 2000) proposed a way to use the JHD method to independently verify the validity of the resultant 3-D velocity models obtained from 3-D tomographic inversion. In this method, synthetic arrival times are calculated based on independently determined 3-D velocity models and the actual event-station distribution. The JHD technique is then applied to the synthetic data to relocate the events and to generate synthetic station corrections. The comparison of the observed and synthetic station corrections and the patterns of the relocated earthquakes will give an adequate assessment of the reliability of the results from the 3-D inversion. The three-dimensional $P$ - and $S$-wave velocity models of Kim et al. (2005) have been used to generate synthetic arrival times with the same event-station geometry in the actual data sets for the groups G1 to G4. The 3-D $V_{P}$ and $V_{S}$ models were determined by the inversion of local earthquake data recorded by the CWB seismic net- 




121.3121 .4121 .5121 .6

(a)

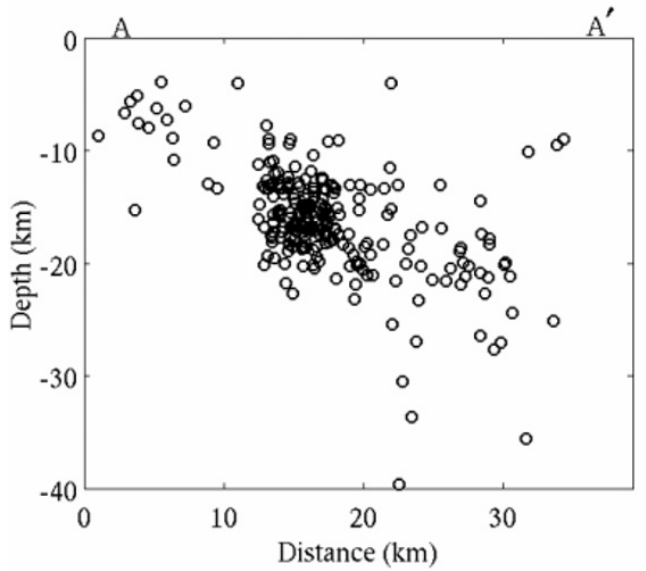

(c)

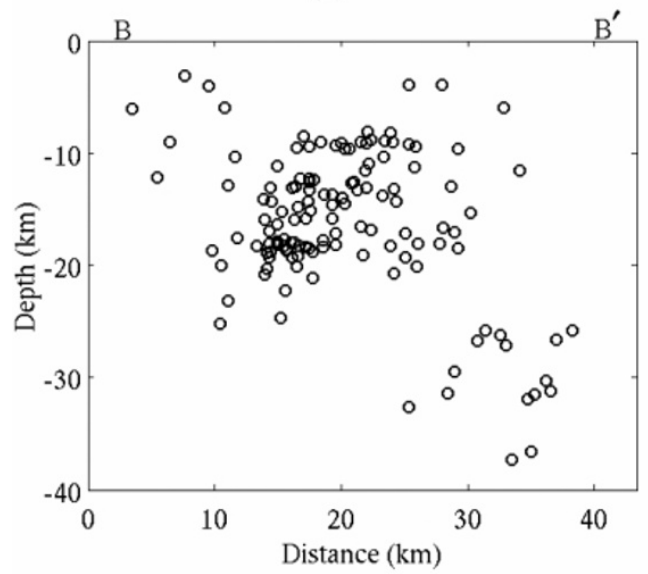

(e)

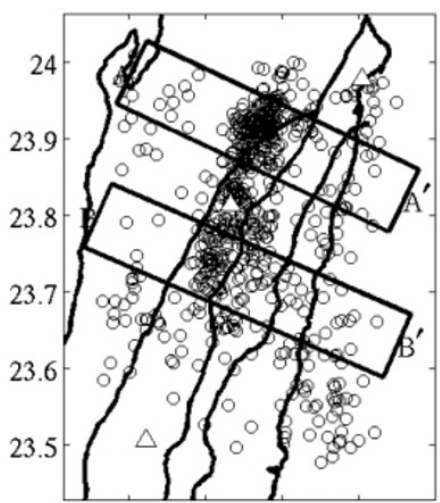

121.3121 .4121 .5121 .6

(b)



(d)

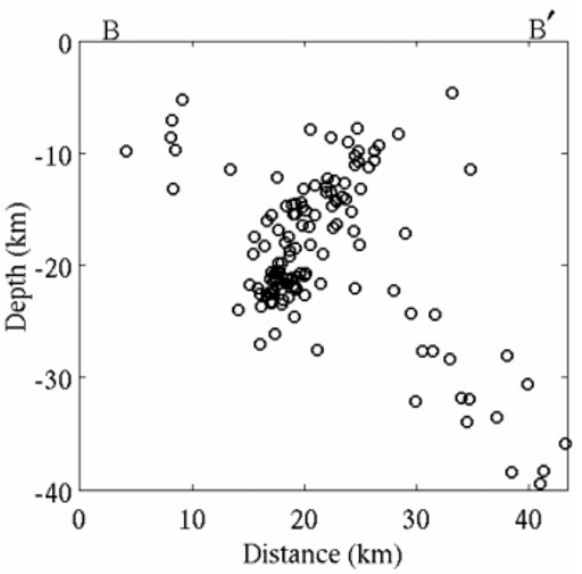

(f)

Fig. 6. Earthquake relocation using the JHD technique for the events in Group 2. Map views of (a) initial earthquake locations determined and reported by the CWB, and (b) relocated epicenters after JHD relocation. Cross sectional views of the initial earthquake hypocenters along A-A' and along $\mathrm{B}-\mathrm{B}^{\prime}$ by the CWB and by the JHD relocation are shown in (c) and (d), and (e) and (f), respectively.

work and two dense local seismic arrays.

JHD $P$ - and $S$-wave station corrections obtained from the synthetic data set are presented along with the corrections derived from the actual data sets (Figs. 3, 5, 7, and 9). The comparison reveals that the synthetic JHD $P$ - and $S$-wave station corrections are very similar to those obtained from the actual data sets. Significant features reproduced in the synthetic station correction patterns include: (1) large negative station corrections along the Central Mountain Range, (2) large positive station corrections in the western Foothills, (3) small positive station anomalies along the Longitudinal Valley and Coastal Range, and (4) large positive station corrections in the Pingtung Basin in southwestern Taiwan. The observed sharp changes in the station corrections across the Chao-Chou fault have been successfully preserved in the results using synthetic data for Group 4. There are, however, minor inconsistencies in the magnitude of the JHD $P$ - and $S$-wave station corrections between the actual and the synthetic data. The JHD $S$-wave station corrections for the synthetic data span a wider range 

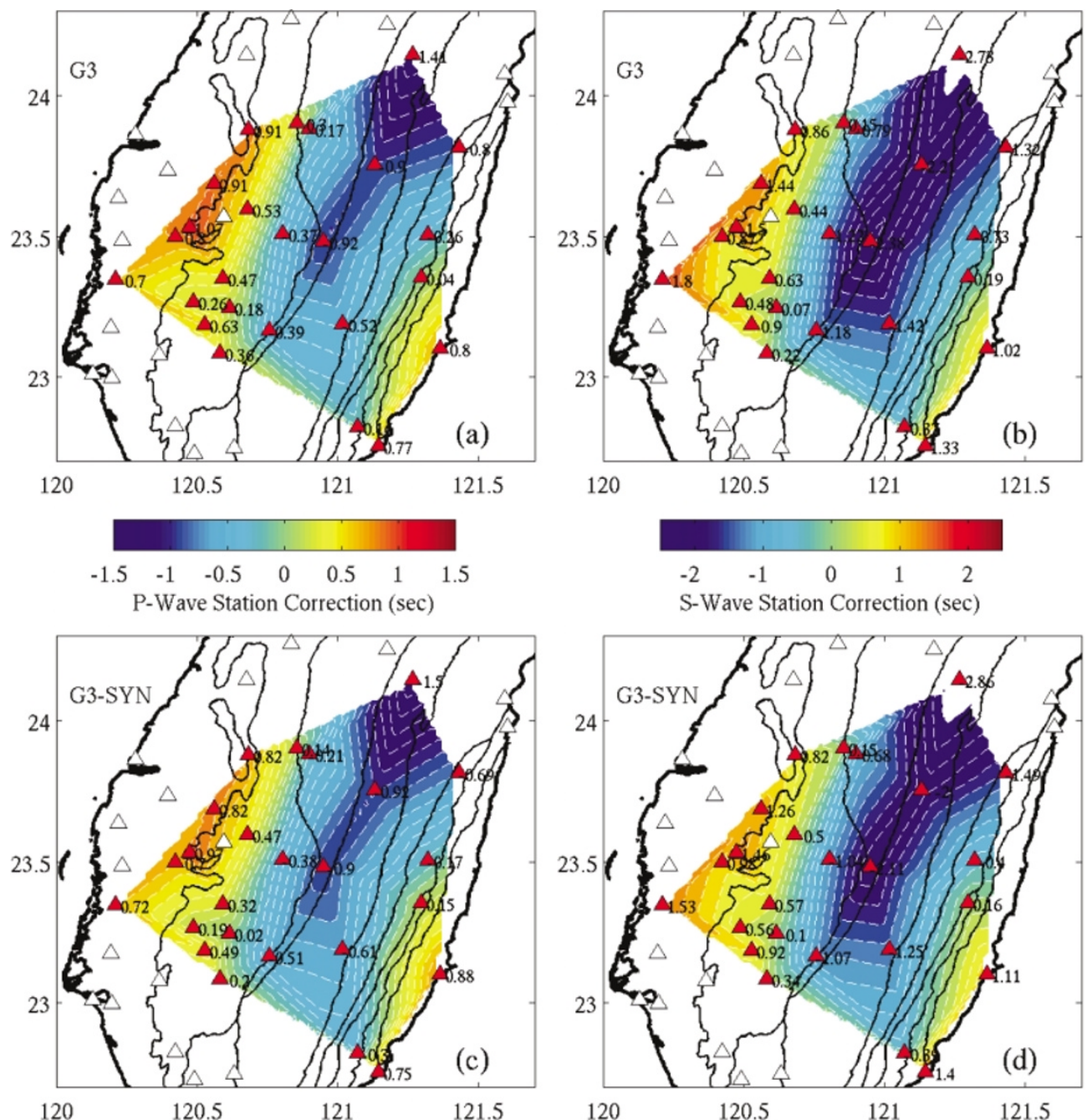

Fig. 7. Same as Fig. 3 but for Group 3.

(from -1.73 to +2.51 ) than the actual JHD $S$-wave station corrections (from -1.2 to +1.71 ). This observation may imply that the 3-D velocity models used in the synthetic arrival time calculation represent well the pattern of velocity variations in the real earth but with minor discrepancies in magnitude, especially in the $S$-wave velocity field. Some stations in this group are located at the southwestern edge of the CWB seismic network. The area also has less seismicity compared to the surrounding regions. Reconstruction of the 3-D velocity models from the 3-D tomographic inversion (Kim et al., 2005) may be subjected to a decrease in resolution in some areas due to insufficient ray coverage.

In general, the patterns of relocated seismicity using synthetic data are comparable to the observed ones for most groups. However, a minor difference in the horizontal relocation pattern of events in Group 1 has been observed. It seems that the JHD relocations of the actual data are scattered more than those of synthetic ones. This observation may imply that the actual earth may be more complex than the models of Kim et al. (2005) predict.

\subsection{Relocated seismicity and subsurface structure}

Using the observed and the synthetic travel time data, earthquake hypocenters in both cases are less scattered after relocation using the JHD technique. Several cross sections are shown to demonstrate the improvements in earthquake locations after the JHD analysis (Figs. 4, 6, 8 and 10). The pattern of relocated hypocenters in Group 1 shows an eastdipping shallow cluster and a west-dipping deeper cluster (Fig. 4). Chen et al. (2002) relocated the $1999 M_{w}=7.6$ Chi-Chi earthquake sequence and found a similar pattern in the study area. They interpreted this seismicity pattern as a conjugated fault system based on the focal mechanisms and hypocenter distribution.

The subsurface structures responsible for the seismicity inferred from the relocated hypocenters are presented in Fig. 11 for Group 2. It is evident that active faults can be delineated by the distribution of the relocated hypocenters, while they are not as clear from the initial locations. A steeply northwest dipping fault can be identified from the linear clustered seismicity shown in cross section B-B' in Fig. 11. For the JHD relocated events, we searched their source parameters determined by BATS (Broadband Array for Taiwan Seismology) to explore the sense of fault motion defined by the relocated seismicity. BATS routinely determines earthquake source parameters for moderate to large earthquakes $(M>4.0)$ occurring in the region since 1995 (Kao and Jian, 1999; Kao et al., 2001; Kao et al., 2002a, b; Liang et al., 2003). A focal mechanism deter- 


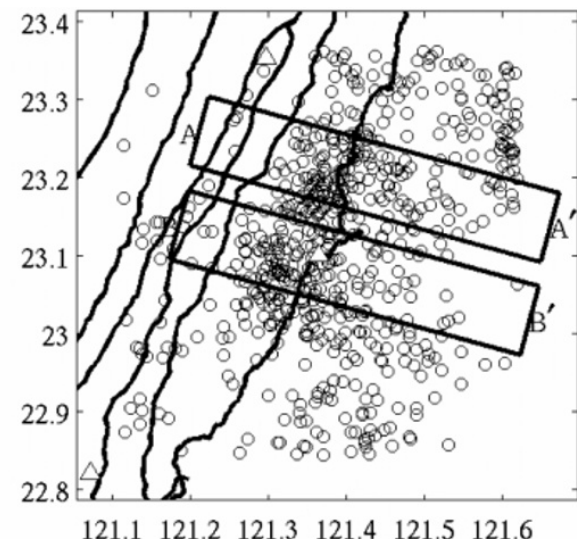

(a)

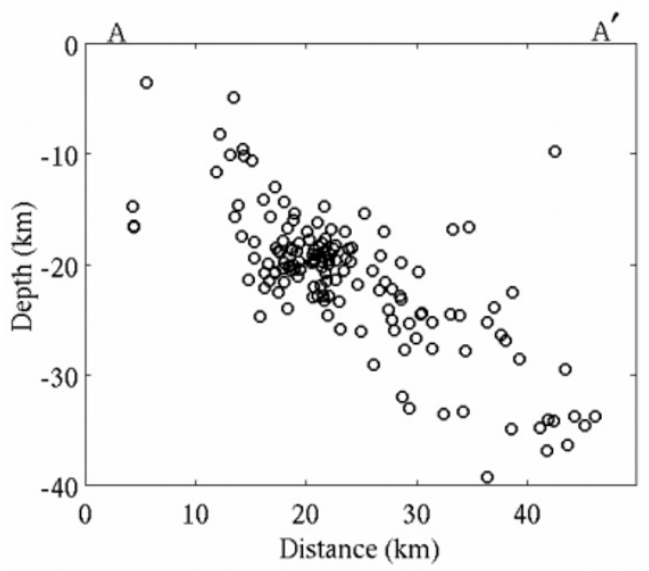

(c)

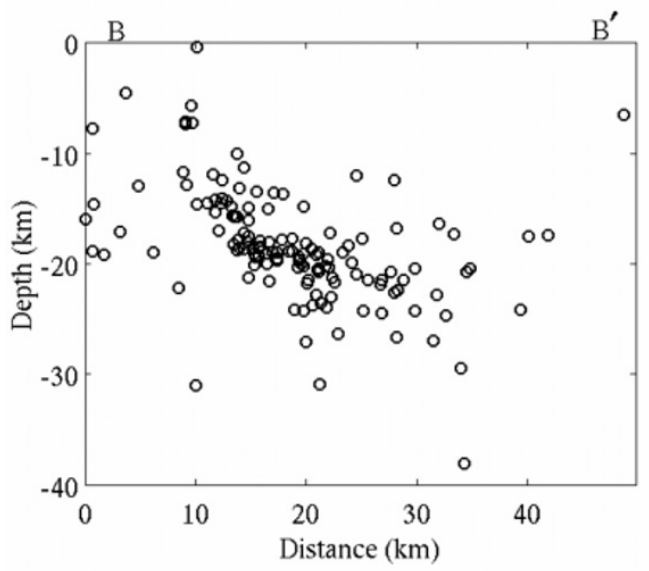

(e)

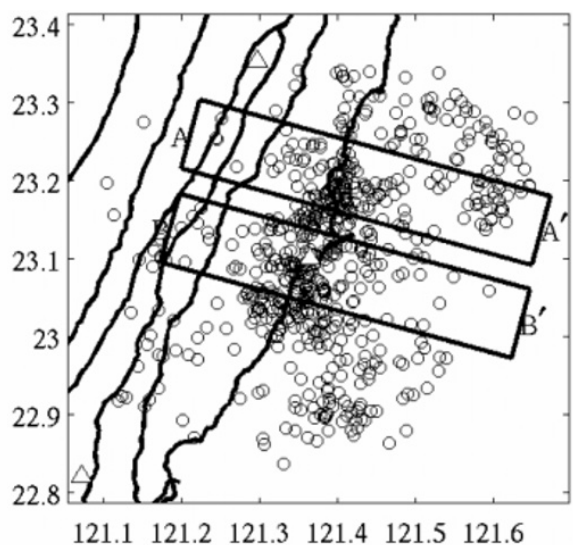

(b)

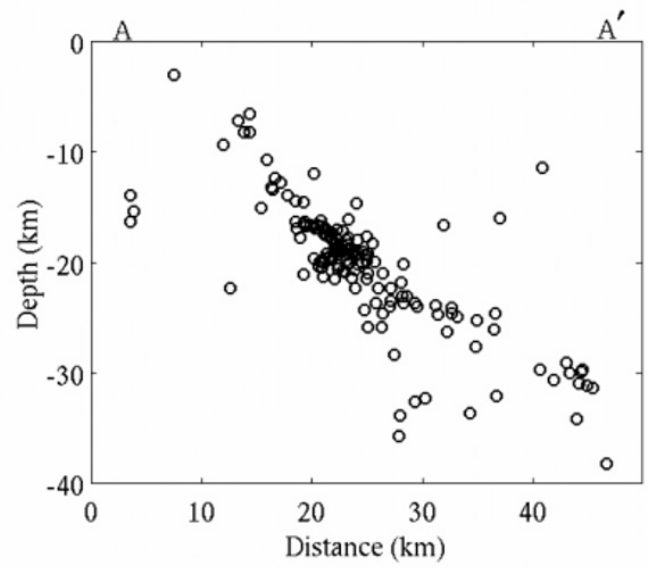

(d)

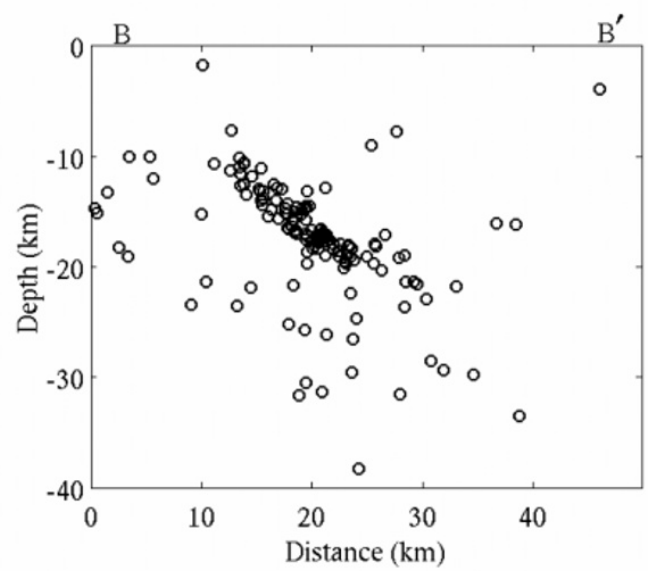

(f)

Fig. 8. Earthquake relocation using the JHD technique for the events in Group 3. Same as Fig. 6 but for Group 3.

mined by BATS is shown in a lower hemisphere projection and in a cross section view of the focal sphere along B-B' in Fig. 11(a) and (b), respectively. The fault plane is consistent with a nodal plane based upon the distribution of relocated hypocenters. The focal mechanism with relocated seismicity clearly shows that the fault ruptured in a thrust manner.

Another major subsurface structure has been identified by the relocated hypocenters of Group 3 in the southern Longitudinal Valley and Coastal Range (Fig. 12). The most concentrated east-dipping seismicity occurs at depths between 10 and $30 \mathrm{~km}$ (Fig. 12). Three focal mechanism so- lutions determined by BATS are shown. The spatial distribution of the relocated seismicity and focal mechanism solution indicates that a thrust fault is responsible for recurrent earthquakes in the region. A recent study using the program HypoDD (Waldauser and Ellsworth, 2000) and events in the same area shows similar results (Kouchen et al., 2004).

Although the Chao-Chou fault has long been recognized due to its spectacular topographic feature, the seismic activity along the fault seemed rather dispersed. However, after the relocation of earthquakes in Group 4 using the JHD method, the seismicity pattern presents a sharper image of 

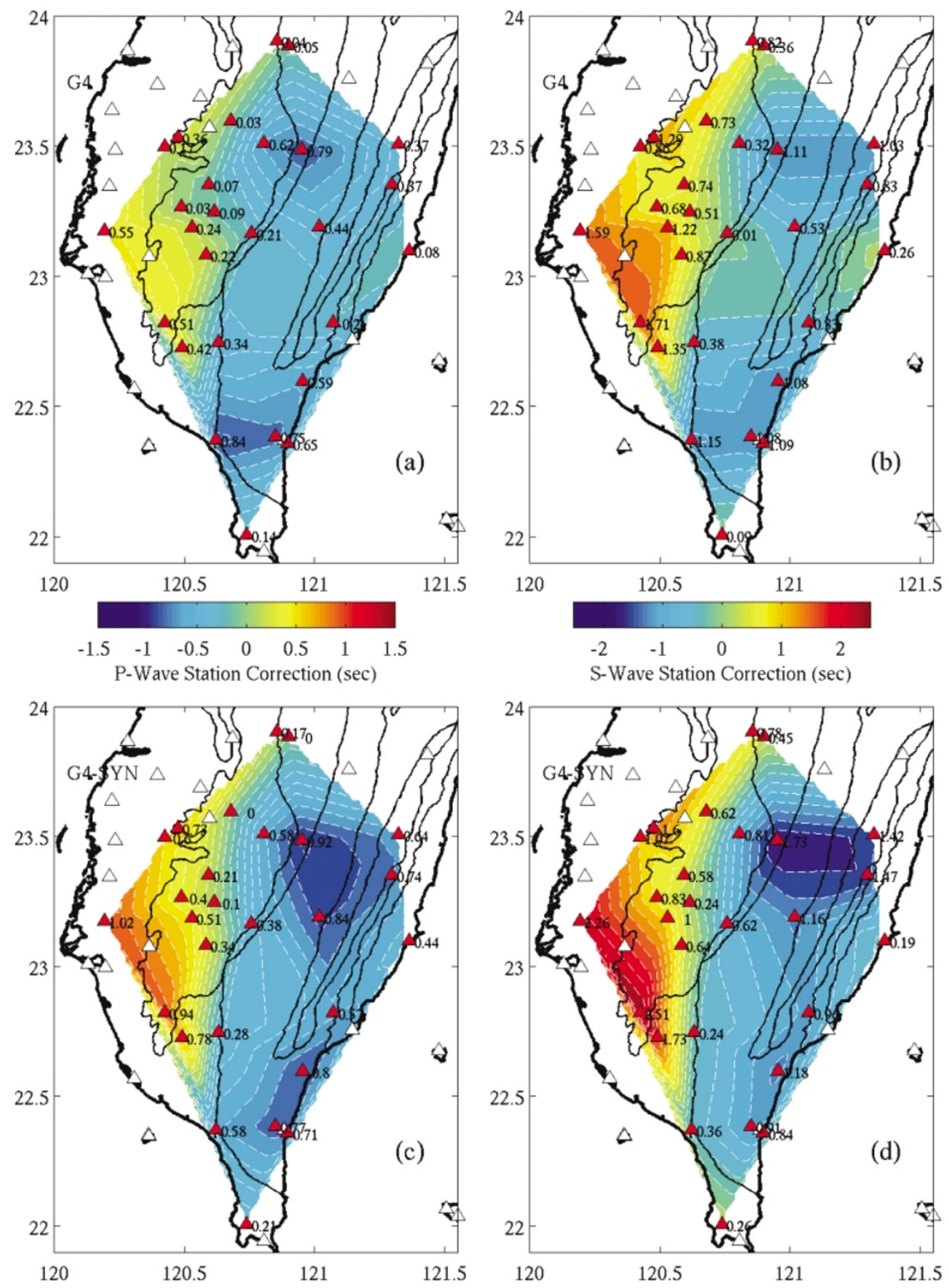

Fig. 9. Same as Fig. 3 but for Group 4.

high angle faulting, which is consistent with previous results of Yen and Tien (1986).

6.3 Station corrections and lateral velocity variations

Many previous studies show that variations in station corrections have a close relationship with lateral velocity variations (Pujol, 1992; Pujol, 1996; Pujol, 2000). JHD results for all four groups in this study show a very wide range of $P$ - and $S$-wave station corrections. In general, the patterns of the $P$ - and $S$-wave JHD station corrections mimic the NNE-SSW trending surface geology. It is also observed that the variation of station corrections within each tectonic unit is relatively small. Thus, relatively uniform or small variation is expected within each tectonic unit, while dis- tinct differences among different tectonic units are persistently observed. We examined the patterns of JHD station corrections and their variations related to the known surface geology.

Inspection of the distribution of JHD station correction for Group 1 shows that subsurface materials beneath the Central Mountain Range have a higher velocity than materials beneath the Western Foothills and Coastal Plain have. This inference agrees very well with the observations from surface geology. The Taichung basin to the west of Group 1 is filled with more than 5,000 meter of low velocity sediment or sedimentary rocks (Ho, 1988), while highly metamorphosed rocks can be found in places to the east of Group 


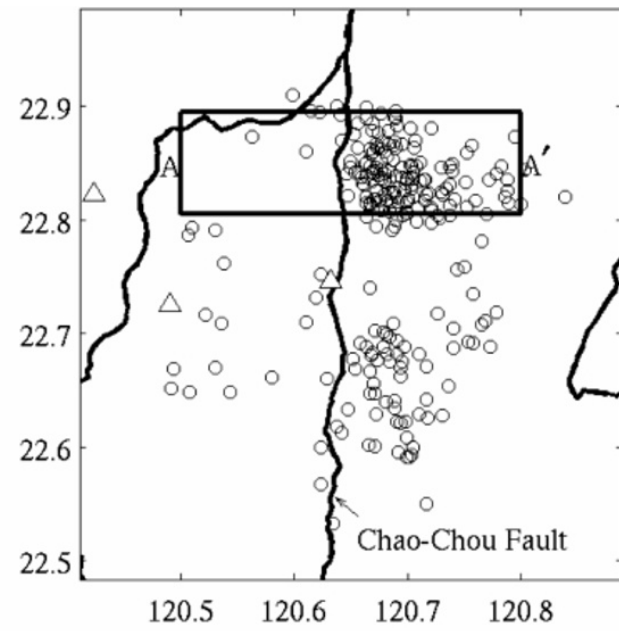

(a)



(c)



(b)

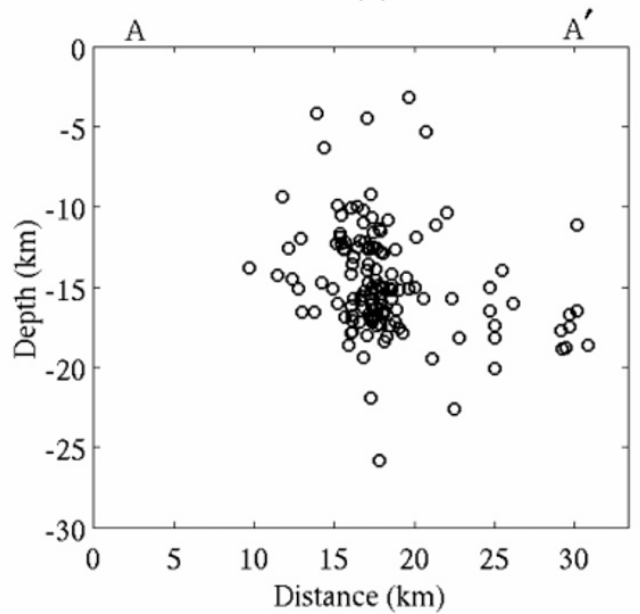

(d)

Fig. 10. Earthquake relocation using the JHD technique for the events in Group 4. Same as in Fig. 6 but for Group 4.

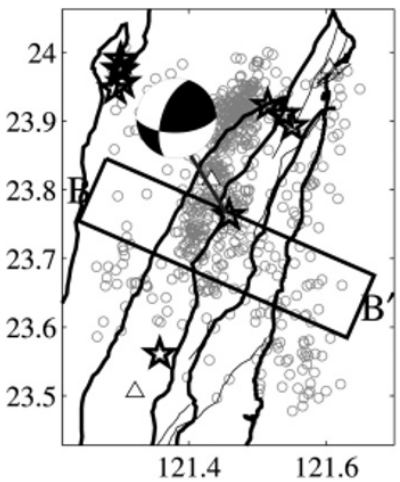

(a)



(b)

Fig. 11. Relocated earthquake hypocenters (a) in a map view and (b) in a cross-sectional view along B-B' in the northern Longitudinal Valley and Coastal Range. A seismogenic subsurface structure deduced from relocated earthquake hypocenters is shown by a dashed line. A focal mechanism solution determined by BATS is also shown in a lower-hemisphere projection in (a) and in a cross-sectional view in (b). The nodal plane corresponding to the fault plane can be inferred based on the relocated seismicity pattern. The focal mechanism with relocated seismicity clearly shows that the fault ruptured in a thrust manner. Stars show BATS earthquake locations.

1. The shift of the JHD relocated hypocenters toward the west or northwest also supports the same inference: when lateral velocity variations exist, earthquake locations using a 1-D homogeneous layered velocity model will most likely be biased and shifted toward the anomalous region of higher velocity. The inclusion of station corrections in the JHD relocation reduces the mislocation due to the existence of lateral structural variations. The JHD relocated hypocenters will be shifted away from the region of higher velocity anomaly and will have improved relative locations, al- 


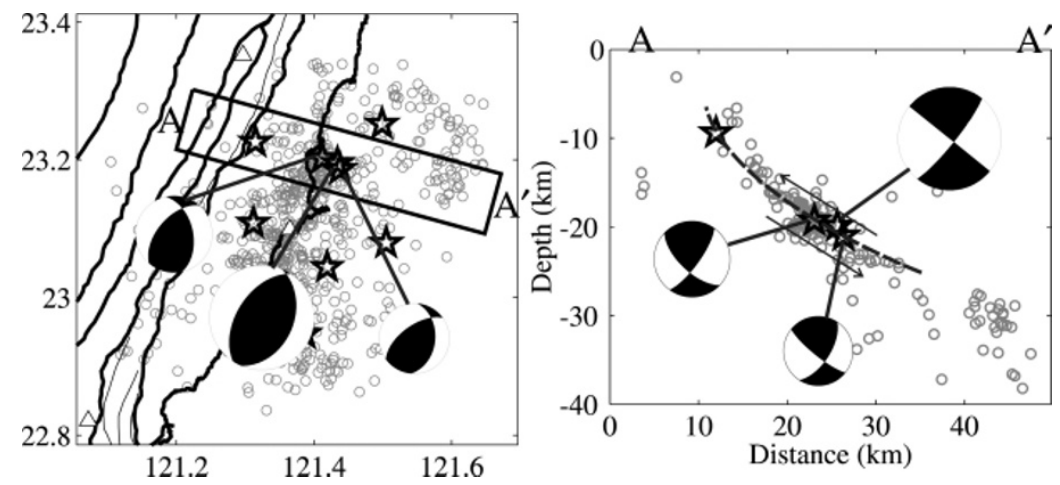

Fig. 12. Same as in Fig. 10 but for A- $\mathrm{A}^{\prime}$ in the southern Longitudinal Valley and the Coastal Range.

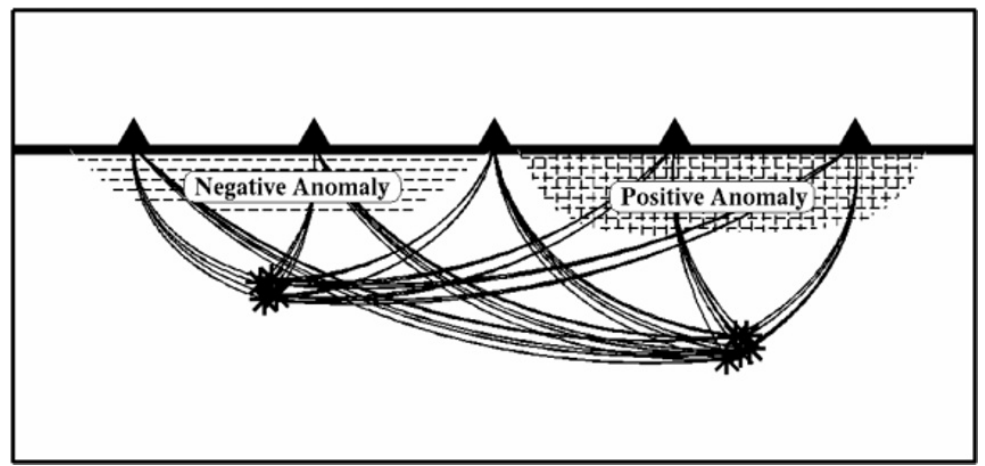

Fig. 13. Schematic view of ray paths that emanate from the clustered earthquakes to surface stations. Rays arriving at a station from different clusters share common travel paths only in the upper crust near the station. Consistent patterns of positive and negative station corrections indicate that upper crust, where two or more clusters of rays have traveled through, is responsible for the JHD station correction anomaly.

though a small systematic shift may also affect the JHD locations (i.e., Pujol, 1996).

A major low velocity basin structure is located in southern Taiwan in the Pingtung basin. This basin is bounded by the Chao-Chou fault to the east, from where a subset of earthquakes in Group 4 was selected. Although the CWB station coverage around the selected Group 4 earthquakes is not as good as that in the other regions in Taiwan, station corrections clearly show a rapid change across the fault. Positive station corrections for the stations located to the west of the Chao-Chou fault become suddenly negative corrections for stations to the east of the fault. Analogous to the interpretation for Group 1, this observation confirms the existence of lower velocity materials to the west and higher velocity materials to the east of the Chao-Chou fault.

The patterns of station corrections for Group 2 and Group 3 reveal that the station corrections for the Longitudinal Valley and Coastal Range of eastern Taiwan are higher than those for the Central Mountain Range but lower than those for the Western Foothills and Coastal Plain. One possibility is that the materials beneath the Longitudinal Valley and Coastal Range have lower velocity than those beneath the Central Mountain Range but higher than those beneath the Western Foothills and Coastal Plain. After the JHD relocation, most earthquakes in Group 2 shifted toward the southeast from their initial hypocenters, implying that the materials in the northwest direction have higher velocity than those in the southeast direction. A significant amount of vertical downward shift has also been observed during the relocation of Group 2 earthquakes. This observation implies that the actual velocity in the Group 2 region may be higher than the velocity model used in the routine earthquake location by the CWB. Pujol (2000) and Chen et al. (2001) have reported a similar observation in their studies of earthquake relocation in the New Madrid Seismic Zone using the JHD technique and using 3-D velocity model. They concluded that an improper representation of the thick unconsolidated sedimentary layer in the 1-D velocity model used for the initial locations is responsible for the "pull up" of hypocenters after relocation.

Most of the CWB stations have recorded events from more than two groups selected in the JHD analysis. However, JHD station corrections at a station vary for different groups. The fluctuating JHD station corrections for different groups reflect different degrees of discrepancies between the employed 1-D velocity model and the actual earth structure along the ray paths. Combining information of station corrections from more than 2 clusters of earthquakes provides inferences on the lateral velocity variations in the study areas. Patterns of station corrections for both $P$ - and $S$-waves for all four selected clusters are remarkably similar and consistent, e.g. positive station corrections for the Western Foothills and Coastal Plain, and negative station corrections for the Central Mountain Range. Seismic rays arriving at a station emanating from different clusters share common travel paths only in the upper crust near the stations (Fig. 13). Consistent patterns of positive and negative station corrections further support that upper crustal struc- 
tures, where two or more clusters of rays have converged, are probably responsible for the observed JHD station corrections. Thus, the pattern of JHD station corrections indeed portrays the major lateral velocity variations in the study areas and is thoroughly consistent with the observed surface geology.

\section{Conclusions}

The JHD technique has been applied to four earthquake clusters. Earthquake hypocenters are generally more clustered after the JHD relocation, which can then be correlated with subsurface structures responsible for the regional seismicity. Significant linear seismicity patterns resulting from the relocations include steep west-dipping seismicity beneath the western Central Mountain Range, steep northwest-dipping seismicity beneath the northern Longitudinal Valley, gentle east-dipping seismicity beneath the southern Longitudinal Valley, and vertical or high-angle east-dipping seismicity beneath the Chao-Chou fault. Results from the JHD relocations also show that the original earthquake locations determined using a simple 1-D homogeneous layered velocity model are subjected to relatively large horizontal and vertical shifts after the lateral velocity variations are properly accounted for during the JHD relocation. This observation implies that systematic errors may exist in the earthquake hypocenters of the CWB catalog due to the over-simplification of a complex earth structure introduced by a simple $1-\mathrm{D}$ velocity model.

The patterns of the JHD station corrections mimic the NNE-SSW trending surface geology. Significant changes of station corrections are observed across tectonic units and can be attributed to the corresponding changes in lithology across the boundaries. Relatively uniform station corrections inside each tectonic unit, on the other hand, imply that the internal structure or lithology within each tectonic unit is relatively uniform with small lateral structural variations. The patterns of the JHD station corrections can also provide additional a priori information to construct better initial models to improve the resolution of a 3-D velocity inversion, especially important for the upper crustal structure. It is obvious from this study that the upper most crust must be responsible for most of the observed station corrections from the JHD analysis. This part of the earth is, however, usually poorly resolved in any traditional 3-D inversion due to nearly parallel and vertically incident seismic rays to the surface stations. Thus, the observed JHD station corrections can provide essential constraints to improve the resolution of the shallow part of the earth's structure. Furthermore, the $P$ - and $S$-wave station correction patterns for all four selected earthquake clusters consistently show positive JHD station corrections for stations on the Western Foothills and Coastal Plain and negative corrections for stations on the Central Mountain Range. This observation further support the interpretation that materials in the upper crust beneath the Central Mountain Range have higher velocities than those beneath the Western Foothills, consistent with the observed surface geology.

Acknowledgments. We thank the CWB of Taiwan for providing arrival time data from its island-wide seismic network. Critical reviews and comments by two anonymous reviewers are highly appreciated. This study was sponsored by the State of Tennessee Center of Excellence Program at the University of Memphis. One of the authors (K.H.K.) was supported by the National Science Council of Taiwan, under grants NSC93-2119-M-001-016, through the Institute of Earth Sciences, Academia Sinica for his post-doctoral research. This is CERI contribution number 496. This study was partially supported by the EEZ project of Korea Government, Ministry of Maritime Affairs and Fisheries.

\section{References}

Angelier, J., H.-T. Chu, and J.-C. Lee, Shear concentration in a collision zone: kinematics of the Chihshang Fault as revealed by outcrop-scale quantification of active faulting, Longitudinal Valley, eastern Taiwan, Tectonophysics, 274, 117-143, 1997.

Chen, H., J.-M. Chiu, J. Pujol, S.-C. Chiu, K.-H. Kim, and M. Withers, A new program for local earthquake locations in the New Madrid seismic zone using a 3-dimensional Vp and Vs velocity model, Seism. Soc. Am. Eastern Section Program \& Abstract, 73rd Annual Meeting, 3, 2001.

Chen, H., J.-M. Chiu, J. Pujol, K.-H. Kim, K.-C. Chen, B.-S. Huang, Y.-H. Yeh, S.-C. Chiu, and M. Withers, A New Algorithm for Local Earthquake Location using 3-dimensional Vp and Vs Models-Test Examples in the Central USA and Taiwan Regions, Bull. Seism. Soc. Am., 2005 (in review).

Chen, K.-C., B.-S. Huang, J.-H. Wang, and H.-Y. Yen, Conjugate thrust faulting associated with the 1999 Chi-Chi, Taiwan, earthquake sequence, Geophy. Res. Lett., 29, 10.1029/2001GL014250, 2002.

Chen, K.-P., Study of Shallow Structure beneath Kaoshiung-Pingtung Region using Local Earthquake Data, Institute of Geophysics, National Central University, 166 pp., 1998.

Chen, Y. L., Three-dimensional velocity structure and kinematic analysis in the Taiwan area, National Central University, 172 pp, 1995.

Douglas, A., Joint epicentre determination, Nature, 215, 47-48, 1967.

Ho, C. S., An Introduction to the Geology of Taiwan Explanatory Text of the Geologic Map of Taiwan, Central Geological Survey/The Ministry of Economic Affairs, 1988.

Kao, H. and P.-R. Jian, Source parameters of regional earthquakes in Taiwan; July 1995-December 1996, Terr. Atmos. Ocean. Sci., 10, 585604, 1999.

Kao, H., Y.-H. Liu, and P.-R. Jian, Source parameters of regional earthquakes in Taiwan; January-December, 1997, Terr. Atmos. Ocean. Sci., 12, 431-439, 2001.

Kao, H., Y.-H. Liu, S.-C. Chen, and W.-T. Liang, Source parameters of regional earthquakes in Taiwan; January-December, 1998, Terr. Atmos. Ocean. Sci., 13, 197-204, 2002a.

Kao, H., Y.-H. Liu, W.-T. Liang, W.-P. Chen, C.-Y. Wang, B.-S. Huang, C. Wang, and H.-W. Chen (eds.), Source parameters of regional earthquakes in Taiwan; 1999-2000 including the Chi-Chi earthquake sequence, Institute of Earth Sciences Academia Sinica, Taipei, Taiwan, 2002b.

Kim, K.-H., J.-M. Chiu, J. Pujol, K.-C. Chen, B.-S. Huang, Y.-H. Yeh, and P. Shen, Three-dimensional $V_{P}$ and $V_{S}$ structural models associated with the active subduction and collision tectonics in the Taiwan region, Geophys. J. Int., 162, 204-220, 2005.

Kuochen, H., Y.-M. Wu, C.-H. Chang, J.-C. Hu, and W.-S. Chen, Relocation of Eastern Taiwan Earthquakes and Tectonic Implications, Terr Atmos. and Ocean. Sci., 15, 646-666, 2004.

Liang, W.-T., Y.-H. Liu, and H. Kao, Source parameters of regional earthquakes in Taiwan; January-December, 2001, Terr. Atmos. Ocean. Sci., 14, 249-260, 2003.

Mueller, K. and J. Pujol, Three-dimensional geometry of the Reelfoot blind thrust; implications for moment release and earthquake magnitude in the New Madrid seismic zone, Bull. Seism. Soc. Am., 91, 1563-1573, 2001.

Pavlis, G. L. and J. R. Booker, Progressive multiple event location (PMEL), Bull. Seism. Soc. Am., 73, 1753-1777, 1983.

Pujol, J., Comments on the Joint Determination of Hypocenters and Station Corrections, Bull. Seism. Soc. Am., 78, 1179-1189, 1988.

Pujol, J., Joint hypocenter location in media with lateral velocity variations and interpretation of the station corrections, Phys. Earth Planet. Inter., 75, 7-24, 1992.

Pujol, J., Application of the JHD technique to the Loma Prieta, California, Mainshock-Aftershock Sequence and Implications for Earthquake Location, Bull. Seism. Soc. Am., 85, 129-150, 1995.

Pujol, J., An integrated 3D velocity inversion-joint hypocentral determi- 
nation relocation analysis of events in the northridge area, Bull. Seism. Soc. Am., 86, S138-S155, 1996.

Pujol, J., Joint Event Location-The JHD Technique and Applications to Data from Local Seismic Networks, in Advances in Seismic Event Location, edited by C. H. Thurber and N. Rabinowitz, pp. 163-204, Kluwer Academic Publishers, 2000.

Pujol, J. and R. Aster, Joint Hypocenter Determination and the Detection of Low-Velocity Anomalies. An Example from the Phlegraean Fields Earthquakes, Bull. Seism. Soc. Am., 80, 129-139, 1990.

Pujol, J., A. Johnston, J.-M. Chiu, and Y.-T. Yang, Refinement of thrust faulting models for the central New Madrid seismic zone, Eng. Geol., 46, 281-298, 1997.

Ratchkovsky, N. A., J. Pujol, and N. N. Biswas, Relocation of Earthquakes in the Cook Inlet area, South Central Alaska, Using the Joint Hypocenter Determination Method, Bull. Seism. Soc. Am., 87, 620-636, 1997.

Ratchkovsky, N. A., J. Pujol, and N. N. Biswas, Relocation of shallow earthquakes in southern Alaska using Joint Hypocenter Determination method, J. Seismol., 2, 87-102, 1998.

Shih, R. C., C. H. Lin, H. L. Lai, Y. H. Yeh, B. S. Huang, H. Y. Yen, C.-S. Liu, D. L. Reed, and C. Wang, Preliminary crustal structures across central Taiwan from modeling of the onshore-offshore wideangle seismic data, Terr. Atmos. Ocean. Sci., 9, 317-328, 1998.

Shin, T. C., K. W. Kuo, W. H. K. Lee, T. L. Teng, and Y. B. Tsai, A preliminary report on the 1999 Chi-Chi (Taiwan) earthquake, Seism. Res. Lett., 71, 24-30, 2000.

Snoke, A. J. and J. C. Lahr, Locating earthquakes: At what distances can the earth no longer be treated as flat?, Seism. Res. Lett., 72, 538-541,
2001.

Suppe, J., Kinematics of arc-continent collision, flipping of subduction, and back-arc spreading near Taiwan, Memoir. Geol. Soc. China, 6, 2133, 1984.

Tsai, Y.-B., Seismotectonics of Taiwan, Tectonophysics, 125, 17-37, 1986. Waldhauser, F. and W. L. Ellsworth, Fault structure and mechanics of the Hayward Fault, California, from double-difference earthquake locations, J. Geophy. Res., 107, 2054, doi:10.1029/2000JB000084, 2002.

Wang, C.-Y. and T.-C. Shin, Illustrating 100 years of Taiwan seismicity, Terr. Atmos. Ocean. Sci., 9, 589-614, 1998.

Yeh, Y. H., R. C. Shih, C. H. Lin, C. C. Liu, H. Y. Yen, B. S. Huang, C. S. Liu, P. Z. Chen, C. S. Huang, C. J. Wu, F. T. Wu, C.-S. Liu, D. L. Reed, and C. Wang, Onshore/offshore wide-angle deep seismic profiling in Taiwan, Terr. Atmos. Ocean. Sci., 9, 301-316, 1998.

Yen, T. P. and P.-L. Tien, Chaochou Fault in southern Taiwan, Proc. Geol. Soc. China, 29, 9-22, 1986.

Yu, S.-B. and C.-C. Liu, Fault creep on the central segment of the Longitudinal Valley Fault, eastern Taiwan, Proc. Geol. Soc. China, 32, 209-231, 1989.

Yu, S.-B., H.-Y. Chen, L.-C. Kuo, S. E. Lallemand, and H.-H. Tsien, Velocity field of GPS stations in the Taiwan area, Tectonophysics, 274, 41-59, 1997.

K.-H. Kim (e-mail: kwanghee@kordi.re.kr or kwangheekim@gmail. com), J.-M. Chiu, J. Pujol, and K.-C. Chen 